\title{
Regularização fundiária, apropriação privada de terras públicas e resistência camponesa no Sudeste Paraense
}

\section{Land regularization, private appropriation of public lands and peasant resistance in Southeast Paraense}

Marcelo Fernando Terence - Doutor em Geografia Humana, pelo Departamento de Geografia da Universidade de São Paulo (USP). Analista em Desenvolvimento Agrário do Incra/Superintendência Regional do Sul do Pará. Professor do Instituto Federal de São Paulo (IFSP). E-mail: marcelo.terence@ifsp.edu.br

\section{Resumo}

O presente artigo expõe os resultados de uma pesquisa que objetivou identificar e analisar casos de apropriação ilegal de terras públicas federais na mesorregião do Sudeste Paraense. Foram selecionados imóveis rurais localizados em glebas públicas e ocupados por famílias integrantes de movimentos sociais de luta pela terra. A pesquisa foi realizada por meio dos seguintes procedimentos metodológicos: a) Entrevistas com sujeitos sociais envolvidos nos conflitos analisados; b) Pesquisa de documentos em instituições da região, como a Justiça Federal e Estadual, o Incra, a Comissão Pastoral da Terra e o Centro de Pesquisa e Assessoria Sindical e Popular. A partir da análise dos dados coletados, foi constatado que a expansão de atividades econômicas como a pecuária acaba por se servir de formas ilegais de apropriação das terras públicas, e que a atuação do Estado favorece esse tipo de prática em detrimento da destinação destas terras para a reforma agrária.

\section{Palavras-chave}

Regularização fundiária. Grilagem de terras. Sudeste Paraense. Resistência camponesa.

\begin{abstract}
Este artículo presenta los resultados de una investigación que tenía como objetivo identificar y analizar casos de apropiación ilegal de tierras públicas federales en la mesoregión del sureste de Pará. Se seleccionaron propiedades rurales ubicadas en glebas públicas y ocupadas por familias que son miembros de movimientos sociales por la lucha por la tierra. La investigación se llevó a cabo a través de los siguientes procedimientos metodológicos: a) Entrevistas con sujetos sociales involucrados en los conflictos, b) Investigación de documentos en instituciones de la región, como la Justicia Federal y Estatal, Incra, Comisión Pastoral de la Tierra y Centro de Investigación y Asesoramiento Sindical y Popular. A partir del análisis de los datos recogidos, se encontró que la expansión de actividades económicas como la pecuaria terminan utilizando formas ilegales de apropiación de tierras públicas y que la acción del Estado favorece este tipo de práctica en detrimento de la destinación de estas tierras para la reforma agraria.
\end{abstract}

\section{Keywords}

Regularización de tierras. Grilagem de tierras. Sureste de Pará. Resistencia campesina. 


\section{INTRODUÇÃO}

"Se a propriedade é um roubo, como queria um publicista célebre, por que o roubo não há de ser uma propriedade?"

(Machado de Assis)

Neste artigo serão discutidos dois casos de apropriação ilegal de terras públicas no Sudeste Paraense (Mapa 1) que foram ou podem ser favorecidos por medidas legais, visando à regularização fundiária, criadas a partir do ano de $2009^{1}$. Essa mesorregião paraense foi escolhida como local da pesquisa por apresentar um histórico importante da prática de grilagem de terra (OLIVEIRA; FARIA; BUARQUE DE HOLLANDA, 2012, p. 157).

Mapa 1 - Localização dos municípios nos quais se situam os casos analisados

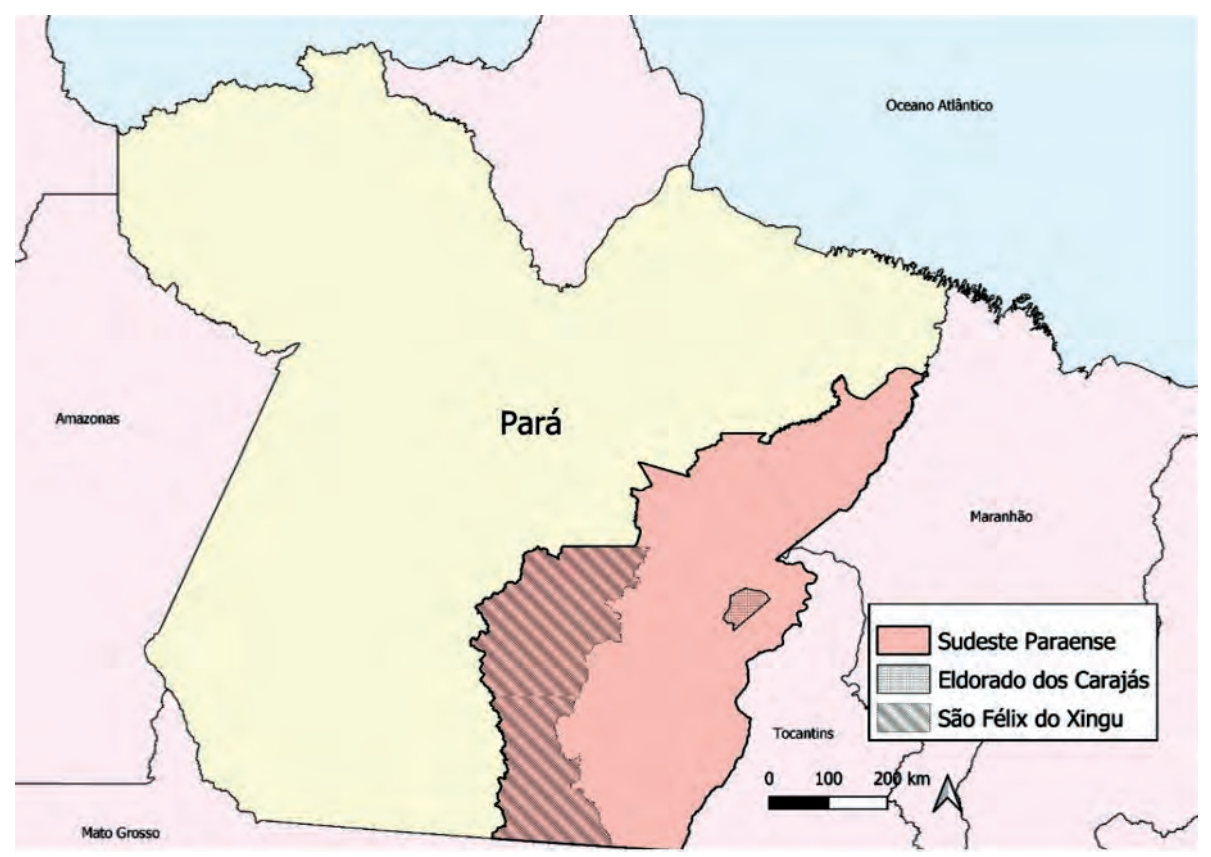

Fonte: organizado pelo autor com base em IBGE (2020).

Nos últimos dez anos, ao invés de combater essas ações de apropriação ilegal de terras públicas, o Estado brasileiro elaborou normas legais voltadas à regularização fundiária de terras que, sendo de domínio da União, estavam ou

O presente artigo reproduz os resultados de um dos capítulos da minha tese de doutorado (TERENCE, 2018). 
estão ocupadas por particulares ${ }^{2}$. As principais delas foram, curiosamente, criadas em governos de distintas - ou mesmo opostas - filiações ideológicas. O governo Lula editou a Medida Provisória (MP) n $n^{\circ} 458$, posteriormente convertida na Lei $\mathrm{n}^{\circ}$ 11.952/09; o governo Temer editou a MP $\mathrm{n}^{\circ} 759$, que foi convertida na Lei $\mathrm{n}^{\circ}$ 13.645/17 e, mais recentemente, o governo Bolsonaro editou a MP n 910, que ainda está tramitando no Congresso Nacional.

$\mathrm{O}$ argumento presente em todas elas, em defesa de seus preceitos, baseiase em três pilares fundamentais: controle do desmatamento, da grilagem e maior segurança jurídica para o investimento nestas terras.

São normas legais que, em essência, compartilham da chamada "legitimação do fato consumado", (CUNHA; TORRES; GUERRERO, 2011, p. 2), ou seja, as apropriações particulares de terras públicas já realizadas até determinada extensão são anistiadas e, assim, ficam proibidas novas ocupações.

Algumas diferenças, entre tais instrumentos legais, podem ser elencadas como, por exemplo: a Lei no 11.952, criada no ano de 2009 e que ensejou a implantação do Programa Terra Legal no ano seguinte, estabeleceu o ano de 2004 como prazo limite para as ocupações serem passíveis de regularização, desde que fossem situadas na Amazônia Legal e com extensão máxima de 1.500 hectares. Já a Lei no 13.645, sancionada no governo Temer, ampliou para 2.500 hectares o limite permitido para regularização e estendeu essa possibilidade para todo o território nacional. Por fim, a MP no 910, editada no governo Bolsonaro, no ano de 2019, estabeleceu como prazo máximo da ocupação passível de ser regularizada o mês de dezembro de 2018 (um ano antes da edição da MP), se o ocupante for o mesmo que requerer a regularização fundiária, ou dezembro de 2014, se houve mudança entre os ocupantes ou detentores da terra nesse período. Tais nuances, no entanto, não elidem o fato de favorecerem sujeitos sociais que se utilizam de processos clássicos da grilagem, como a conhecemos no Brasil, para se apropriarem de vastas e valiosas áreas que, comumente, são destinadas ao agronegócio, sobretudo à pecuária capitalista ${ }^{3}$.

Nos últimos dois governos federais, Temer e Bolsonaro, além das normativas criadas, vêm se dando cada vez mais ênfase nos discursos a favor

2 Todos os três instrumentos legais aqui discutidos abrem a possibilidade da regularização fundiária urbana. Pelo fato deste tipo de regularização possuir características e consequências sociais absolutamente distintas da regularização em áreas rurais, não será discutida nesse artigo.

3 Não por acaso, a mesorregião do Sudeste Paraense ocupa, segundo dados do IBGE de setembro de 2019, o topo no ranking de mesorregiões brasileiras com maior efetivo de rebanho bovino, contando com 13.851 .186 cabeças de gado (IBGE, 2019). 
da regularização fundiária e contra a criação de projetos de assentamentos de reforma agrária, devido a estes últimos serem considerados pouco produtivos. Já as propriedades originadas do processo de regularização fundiária, de maior extensão que os lotes dos PAs, por serem consideradas mais aptas ao agronegócio, são vistas pelas autoridades como mais produtivas ${ }^{4}$.

\section{ASNORMASFUNDIÁRIASE AACUMULAÇÃO ESPACIALMENTE EXPANSIVA NO BRASIL}

A grilagem é a norma da ocupação territorial no Brasil. Desde a introdução do instituto das sesmarias durante o período colonial, a ilegalidade sempre foi a regra no processo de formação da grande propriedade da terra (FORSTER, 2003; NÓVOA, 2000). O mesmo ocorreu quando da criação da chamada Lei de Terras de 1850, a Lei $n^{\circ}$ 601, e ocorre nos processos contemporâneos de regularização fundiária na Amazônia Legal: a norma subsequente é criada para consolidar a ilegalidade cometida na apropriação de terras durante a vigência do instrumento legal anterior (TRECCANI, 2001, p. 27). Tanto o Estado metropolitano português quanto o Estado nacional sempre foram lenientes quanto à fiscalização e permissíveis em relação à anistia da grilagem. Por isso mesmo, na maior parte destas leis, o beneficiário da ocupação é denominado "posseiro", seja ele de fato um pequeno ocupante de terras públicas ou um grande latifundiário.

Em relação às sesmarias, por exemplo, a imposição de restrições à apropriação particular das terras como limites à extensão das mesmas (três léguas de comprimento e uma de largura), a cobrança de foro por parte da Coroa Portuguesa ou mesmo a necessidade de confirmação das concessões pelo rei português só fizeram aumentar a ilegalidade e, segundo Silva (1996, p. 52), não houve regramento efetivo na ocupação das terras, posto que foram apropriadas de acordo com a força e a vontade dos poderosos ${ }^{5}$.

\footnotetext{
A expansão da reforma agrária, de fato, foi interrompida. Por outro lado, a regularização fundiária foi implementada timidamente até o momento, seja por dificuldades operacionais do Incra ou por questionamentos legais por parte de órgãos como o MPF.

5 Nóvoa descreve um dos abusos cometidos pelos fazendeiros na apropriação de terras: "A Carta Régia de 1612 aconselhava que 'quanto menos terra se distribuísse, maiores seriam as possibilidades de aproveitamento', afinal os abusos como o cometido na concessão a Brás Cubas, cuja sesmaria abrangia área que extrapolava a extensão dos atuais municípios de Santos, Cubatão e São Bernardo do Campo, deveriam ser coibidos" (NÓVOA, 2000, p. 34). Na mesma linha, Motta (1998) se refere às práticas ilegais cometidas por sesmeiros como o retalhamento para a venda ilegal antes do término do prazo de inalienabilidade, doação de sesmarias em nome de "laranjas" e o não cumprimento da cláusula de produtividade.
} 
Após a independência nacional, a implantação da Lei nº 601, no ano de 1850, estabeleceu regras para ocupações posteriores à data da regulamentação desta, sobretudo a necessidade de compra como forma universal de se adquirir terras públicas, e anistiou, nos seguintes termos, as ocupações antes tidas como ilegais:

Art. $4^{\circ}$ Serão revalidadas as sesmarias, ou outras concessões do Governo Geral ou Provincial, que se acharem cultivadas, ou com princípios de cultura, e morada habitual do respectivo sesmeiro ou concessionário, ou do quem os represente, embora não tenham sido cumpridas quaisquer das outras condições, com que foram concedidas.

Art. $5^{\circ}$ Serão legitimadas as posses mansas e pacíficas, adquiridas por ocupação primária, ou havidas do primeiro ocupante, que se acharem cultivadas, ou com princípio de cultura, e morada, habitual do respectivo posseiro, ou de quem o represente (BRASIL, 1850, não paginado).

O objetivo principal desta lei foi manter trabalhadores (ex-escravizados ou imigrantes) como não proprietários e absolutizar a propriedade privada da terra, descartando as condicionantes que as sesmarias impunham. Deste ponto de vista, a Lei n ${ }^{\circ} 601$ foi bem-sucedida ao dificultar a posse camponesa e anistiar as grandes detenções de terras.

Nos dizeres de Silva, a referida lei realizou a transição da forma de apropriação determinada pelas regras das sesmarias "para outra, a forma burguesa, contratual, que tornava o proprietário no sentido romano do use, abuse e retirava do Estado a possibilidade de reaver as terras" (SILVA, 1996, p. 160).

Criou-se, assim, no Brasil, um mercado de terras com características capitalistas sem que, por isso, cessasse a apropriação ilegal das terras devolutas pertencentes ao patrimônio público. Sedimentou-se ainda, no país, um padrão de distribuição fundiária favorecedor de um tipo de acumulação específico, uma acumulação espacialmente expansiva ${ }^{6}$, que cria e recria historicamente, por meios não determinados diretamente pelos imperativos do mercado, as condições para a expansão territorial da reprodução propriamente capitalista ${ }^{7}$. Nessa

\footnotetext{
Este conceito vem sendo trabalhado pelo autor como uma das formas da acumulação primitiva, levando em conta o modo como este último conceito é pensado por autores como De Angelis (2018), que ressalta a acumulação primitiva como um processo contínuo no interior do desenvolvimento capitalista. O que se quer ressaltar com a ideia de acumulação espacialmente expansiva é essa característica de apropriação territorial ainda muito presente nos processos de acumulação no Brasil, devido às características muito próprias da formação territorial do país.

7 Podem ser citados como exemplos históricos desses processos de produção de capital, via a apropriação de terras públicas, a expansão cafeeira na região sudeste do Brasil, estudada por Martins (1985) e a expansão do cultivo da soja no estado do Mato Grosso, estudada por Oliveira (2016).
} 
forma de acumulação, que ocorre continuamente ao desenvolvimento capitalista, prevalecem a fraude, a violência, a criação de normas legais ou o descumprimento da lei, impondo as condições para a exploração capitalista.

Até o ano de 1891, a Lei $n^{\circ} 601$ foi a norma que prevaleceu em relação à apropriação de terras públicas denominadas de devolutas, ou seja, não discriminadas em nome de ente público ou privado. A partir dessa data, com a proclamação da primeira Constituição Republicana, as terras devolutas passaram para o controle dos estados da federação ${ }^{8}$. A seguir serão apresentados, resumidamente, alguns instrumentos legais criados e implantados para destinação de terras públicas pelo estado do Pará, onde se situam os dois casos analisados neste artigo.

\section{A LEGISLAÇÃO PARAENSE SOBRE TERRAS DEVOLUTAS: O FAVORECIMENTO ÀS GRANDES APROPRIAÇÕES PRIVADAS DE TERRAS PÚBLICAS}

A primeira norma importante criada pelo Estado do Pará para administrar as terras devolutas em seu território foi o Decreto $n^{\circ} 410$, de 08/10/1891, o qual manteve a lógica de se anistiar as ilegalidades do passado em relação à ocupação de terras públicas, como expressa em seu preâmbulo: “[...] convém facilitar aos posseiros de boa-fé título de propriedade das terras que ocupam, embora não tivessem sido cumpridas as disposições da Lei $\mathrm{n}^{\circ}$ 601, de 18 de setembro de 1850” (PARÁ, 1891, não paginado).

Esse decreto foi o primeiro de uma sucessão de normas que, por décadas, anistiaram apropriações caracterizadas como ilegais em instrumentos legais anteriores, sempre com a promessa de impedir as posses vindouras, mas nunca as impedindo. Pelo contrário, como demonstrado pela bibliografia, a transferência do poder sobre as terras devolutas para a instância estadual facilitou ainda mais a apropriação das mesmas pelas oligarquias locais ${ }^{9}$. Abaixo uma síntese de alguns desses instrumentos legais criados pelo Estado paraense, visando legalizar as apropriações privadas de terras públicas e/ou criar regras para a destinação destas:

8 Constituição Federal de 1891, Art. 64: "Pertencem aos Estados as minas e terras devolutas situadas nos seus respectivos territórios, cabendo à União somente a porção de território que for indispensável para a defesa das fronteiras, fortificações, construções militares e estradas de ferro federais" (BRASIL, 1891, não paginado).

9 Ver Monteiro (1980) e Treccani (2001). 
a) Decreto $n^{\circ}$ 410, de 1891: possibilitou a regularização fundiária por parte do Estado, desde que respeitados os seguintes limites: “em terras de lavoura até 1089 hectares; em campos de criação até 4.356 hectares e em seringais até 545 hectares" (PARÁ, 1891, não paginado). Excedendo-se esse limite, o ocupante poderia comprar as terras junto ao governo estadual. Além disso, considerava a ocupação econômica a mera conservação de seringais e castanhais ou mesmo a criação de gado solto, facilitando a apropriação particular de vastas extensões de terras (MONTEIRO, 1980). O referido Decreto foi ainda responsável por inovar ao criar um inusitado título de posse, emitido mediante mera declaração por escrito do interessado, localizando a área requerida e anotando sua dimensão aproximada.

b) Lei $\mathbf{n}^{\circ}$ 1601, de 1917: concedeu gratuitamente até 25.000 hectares de terras estaduais paraenses para a criação de gado bovino em regiões como o Alto Xingu, o Alto Tocantins, o Rio Araguaia e outras. Passados cinco anos, o ocupante ganhava um título definitivo, se comprovasse a produção das terras, ou poderia ainda as comprar a preço estabelecido em lei, com desconto de 50\%.

c) Lei $\mathbf{n}^{\mathbf{0}}$ 1741, de 1918: em relação à venda de terras estaduais para particulares, estabeleceu o preço do hectare baseado em uma lei do ano de 1892 (100\$000 por 100 hectares) e garantiu, para pagamentos à vista, abatimento de $20 \%$.

d) Lei $n^{\circ}$ 1947, de 1920: criou o denominado aforamento perpétuo, que eliminou os limites para a apropriação privada de terras públicas e estabeleceu um foro anual de $2 \%$ sobre o preço das terras, estipulado no ano de 1892 . Este instrumento legal foi utilizado em grande escala no período para transferir terras públicas para particulares, mediante algumas condicionantes ${ }^{10}$. A mesma lei criou a figura dos arrendamentos anuais.

e) Decreto Estadual no 2.828, de 1937: possibilitou uma interferência ainda maior das oligarquias locais ao transferir para a decisão dos prefeitos municipais "as questões sobre limites e locações de terras de castanhais e outros produtos nativos arrendados pelo Estado", devendo estes apenas comunicar ao poder estadual as medidas tomadas.

Entre eles a necessidade de autorização do Estado e pagamento de uma taxa para a transferência de titularidade e a manutenção da finalidade produtiva: castanhais, seringais etc. Segundo Emmi (1999), tais condicionantes nunca foram respeitadas. 
f) Lei $\mathrm{n}^{\circ}$ 913, de 1954: reintroduziu a figura legal dos aforamentos perpétuos, extintos durante o primeiro governo Vargas. O retorno da possibilidade dos aforamentos foi amplamente utilizado para a concessão de terras públicas no Sudeste Paraense que, nos anos 1950 e 1960, se tornou uma região muito atrativa para toda a sorte de especuladores, grileiros e empresas capitalistas, sobretudo após a inauguração da rodovia Belém-Brasília, no ano de 1960. Apenas no quadriênio 1959-1963, a partir desta normativa, mais de cinco milhões de hectares foram privatizados pelo governo estadual (TRECCANI, 2001, p. 180).

\section{A FEDERALIZAÇÃO DAS TERRAS ESTADUAIS: O GRANDE CAPITAL E A GRILAGEM}

No ano de 1971, durante a ditadura civil-militar instalada no Brasil, foi imposto o Decreto no 1.164, determinando a federalização das "terras devolutas situadas na faixa de 100 quilômetros de largura de cada lado do eixo das rodovias federais na Amazônia Legal” (BRASIL, 1971, não paginado), incluídas aquelas rodovias "em construção ou projetadas", deixando a cargo do então chamado Departamento Nacional de Estradas de Rodagem (DNER) o estabelecimento das rotas e o tamanho de tais estradas. Um verdadeiro confisco ao arrepio da Lei, no entender de Éleres (2002, p. 70).

O estado do Pará e, sobretudo, o Sudeste Paraense tiveram boa parte de seus territórios federalizada devido a tal medida. Foram federalizados 71.738 .000 hectares (setenta e um milhões, setecentos e trinta e oito mil) de terras, $57,24 \%$ do território paraense ${ }^{11}$. É importante ressaltar que, teoricamente, a federalização atingiu somente as terras que permaneciam devolutas, ou seja, aquelas ainda não destacadas do patrimônio público. Assim, todas as terras aforadas ou vendidas pelo Estado paraense não seriam afetadas ${ }^{12}$.

Desta forma, o governo ditatorial pôde, arbitrariamente, implementar sua política de favorecimento à grande propriedade e à denominada "empresa rural" por meio de subsídios, como os concedidos pela Superintendência

11 Com a finalidade de se apropriar das áreas da chamada "Província Mineral dos Carajás", o Governo Federal impôs, de forma complementar, o Decreto 1473/76, ampliando ainda mais a área federalizada.

12 Isso na teoria. Na prática, até áreas aforadas, tidas como intocáveis pelo Iterpa, por entrarem na categoria de "situações juridicamente constituídas", foram alienadas e tituladas pelo Incra e, à sua época, pelo Getat, aumentando ainda mais o caos fundiário no estado do Pará. Ver Éleres (2002). 
de Desenvolvimento da Amazônia (Sudam). Nos planos dos militares, o desenvolvimento econômico das áreas federalizadas, em particular no Sudeste Paraense, deveria ocorrer por meio de duas atividades voltadas para a exportação: a pecuária e a mineração. Torres (2012) cita um dos atos que favoreceu, à época, a privatização de grandes extensões:

Em 6 de junho de 1976, o governo concedera o mais aberto favorecimento à grilagem. $\mathrm{O}$ ministro da Agricultura e o ministro-chefe do todo poderoso Conselho de Segurança Nacional, general Hugo Abreu, assinaram as Resoluções no 005 e 006 do CSN, que adquiriam força de lei. A partir disso, permitia-se a regularização de áreas de até 60 mil ha que tivessem sido adquiridas irregularmente, mas de boa-fé (TORRES, 2012, p. 194).

Os governos militares mantiveram, portanto, a velha tradição de se privatizar e/ou legitimar apropriações ilegais de terras públicas. Para se ter um exemplo da expansão da privatização das terras e da propriedade capitalista, no Município de Marabá, situado no Sudeste Paraense, no período da federalização das terras, números do Incra apontam um importante aumento dos imóveis cadastrados nesse período: 661 em 1972; 954 em 1976 e 2.451 em 1981, com uma área total ocupada pelos imóveis rurais cadastrados de 810.750 hectares, 1.361.621 hectares e 2.977.708 hectares, respectivamente ${ }^{13}$.

Já no governo Sarney, no ano de 1987, finda oficialmente a ditadura civilmilitar, foi criado o Decreto $n^{\circ} 2775$, devolvendo as terras devolutas para o Estado paraense. No entanto, as áreas arrecadadas pelo governo federal no período de vigência do Decreto no 1164/71 e que não foram privatizadas, continuaram sob gestão federal até os dias atuais. No Mapa 2, está a localização das glebas federais no Sudeste Paraense.

No Sudeste Paraense, foram 136 as glebas arrecadadas pelo Incra e pelo Getat, somando um total de 15,2 milhões de hectares. Excetuadas as áreas privatizadas que se encontram dentro destas glebas, as demais são exatamente as áreas visadas pelas normas legais federais criadas desde o ano de 2009, citadas no início deste artigo e que visam à regularização fundiária destas. Nestas glebas estão situados os dois imóveis rurais objetos deste estudo.

\footnotetext{
13 É importante frisar que tal processo foi conflituoso e violento devido ao fato de muitas destas terras vendidas ou regularizadas pelos militares já serem ocupadas por camponeses. Não cabe no espaço deste artigo retratar todo o rico histórico da luta pela terra no Sudeste. Ver, por exemplo, Pereira (2004).
} 
Mapa 2 - Glebas federais arrecadadas no período de vigência do Decreto 1164/71, no Sudeste Paraense

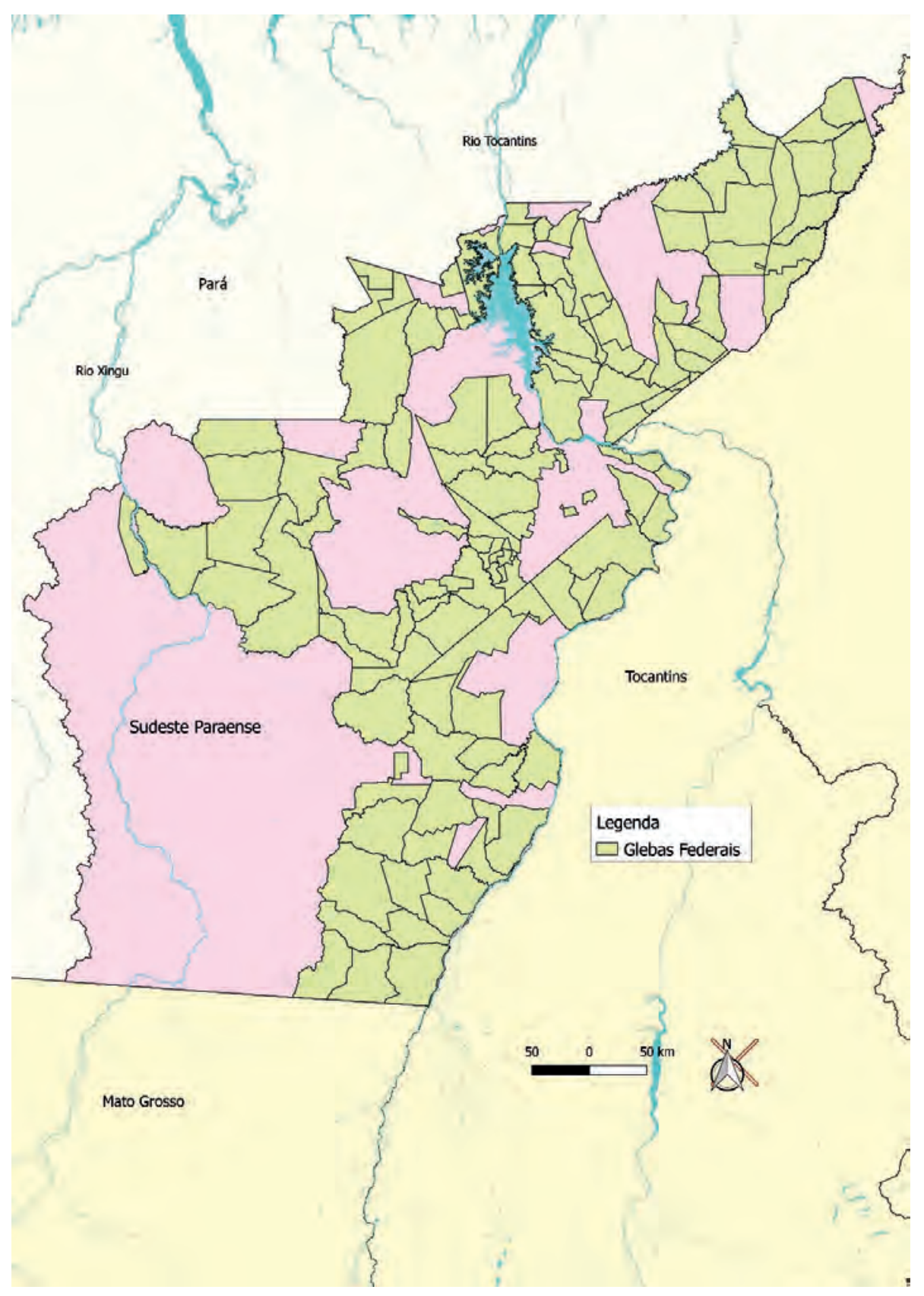

Fonte: organizado pelo autor com base em Incra, 2017. 


\section{MATERIAIS E MÉTODOS}

Foram analisados dois casos concretos envolvendo áreas públicas federais com pedidos de regularização fundiária ao Programa Terra Legal, no Sudeste Paraense. A escolha foi de dois imóveis rurais ocupados pelos movimentos sociais de luta pela terra na região e em relação aos quais foi possível obter informações detalhadas dos processos de regularização fundiária em curso e dos conflitos fundiários ali instalados. Algumas informações para o estudo destes casos foram obtidas por meio de entrevistas com integrantes dos movimentos sociais envolvidos nas ocupações, membros da assessoria jurídica da Comissão Pastoral da Terra (CPT), acampados e funcionários do Incra da Superintendência Regional de Marabá (SR-27) e da Unidade Avançada de Conceição do Araguaia (Uaca).

A maior parte dos dados, no entanto, foi acessada através de processos judiciais referentes aos conflitos, localizados na Vara Agrária de Marabá, e a documentação do Incra e do Programa Terra Legal, localizados na SR-27 e na Uaca. Como casos específicos para a análise, foram escolhidos o Complexo de Fazendas Divino Pai Eterno, localizado no município de São Félix do Xingu, e o Complexo de Fazendas Iraque, localizado no município de Eldorado dos Carajás. A escolha destes casos foi devido ao fato de ambos apresentarem documentação acessível suficiente para a análise e por apresentarem características muito comuns nos casos de grilagem.

O complexo de imóveis rurais denominado Divino Pai Eterno foi visitado no ano de 2007 - no início da ocupação por famílias camponesas - e no ano de 2011, quando a ocupação já existia, em razão de trabalhos realizados a serviço do Incra. Tive oportunidade de entrevistar, no ano de 2017, alguns integrantes da ocupação e a viúva de um dos líderes do acampamento, assassinado em 2015, no município de São Félix do Xingu. O Complexo Iraque não foi visitado, no entanto, em relação ao mesmo, foi possível consultar processos judiciais e processos administrativos do Programa Terra Legal. Dada a riqueza do material obtido, optou-se por sua inclusão na análise aqui realizada.

Por fim, o material cartográfico dos imóveis rurais foi elaborado a partir do Acervo Fundiário do Incra e do Programa Terra Legal, quando foi realizada a sobreposição de mapas referentes às glebas federais, às parcelas que requereram regularização fundiária e aos imóveis certificados pelo Incra, permitindo assim analisar as condições cadastrais das áreas em conflito estudadas. 


\section{RESULTADOS E DISCUSSÃO}

\subsection{O CONFLITO AGRÁRIO NO COMPLEXO DE FAZENDA DIVINO PAI ETERNO, NO MUNICÍPIO DE SÃO FÉLIX DO XINGU}

No ano de 2007, esse complexo de fazendas estava sob o controle de Joaquim do Tato, notório detentor de terras públicas no município de São Félix do Xingu, quando foi ocupado por famílias camponesas organizadas pelo Sindicato dos Trabalhadores e Trabalhadoras Rurais (STTR) do mesmo município ${ }^{14}$. Com o conflito instalado, a área foi vendida, informal e ilegalmente, para o pecuarista José Iris Nunes, proprietário de terras e pecuarista no município de Porangatu/GO, conforme identificação em Laudo de Fiscalização do Incra de 2007. O referido imóvel está parcialmente situado na Gleba Federal Misteriosa, e parcialmente em terras estaduais, como demonstra o Mapa 3.

Mapa 3 - Complexo de Fazendas Divino Pai Eterno

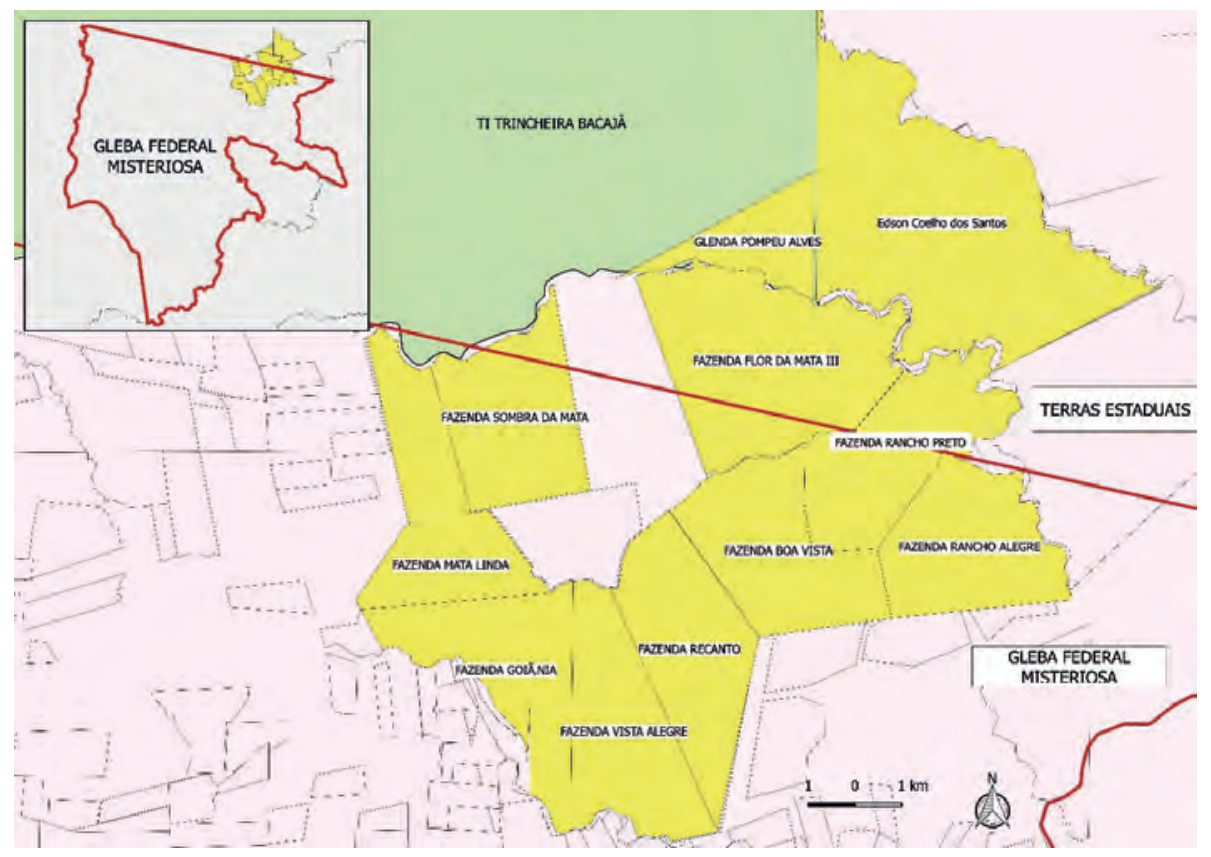

Fonte: Incra/MDA (2017).

14 Sobre a atuação de Joaquim do Tato e mais detalhes sobre a ocupação da fazenda, ver reportagem em Cícero e Barros (2016). 
Fato significativo da importância do movimento social de luta pela terra na denúncia da grilagem na região é que o Incra, após duas vistorias técnicas, ainda atestava em seus relatórios que a área media um total de 2.441 hectares. Foram os integrantes do movimento social que apontaram o fato da fazenda denominada Divino Pai Eterno ser apenas uma parte de um complexo de fazendas e possuir extensão bem maior que a apontada pelo órgão fundiário.

Utilizando-se de uma estratégia clássica da grilagem de terras no Brasil, em meio ao conflito com o movimento de luta pela terra, o Sr. José Íris Nunes optou por fracionar a área e, aproveitando-se das possibilidades oferecidas pelo Programa Terra Legal - que permitia a regularização de até $15 \mathrm{MF}$ ou 1.500 hectares, dividiu-a em nove parcelas, cada uma delas em nome de um preposto e área bem próxima dos limites legais para a regularização à época, conforme o Quadro 1.

Quadro 1 - Fazendas do Complexo Divino Pai Eterno cadastradas no Programa Terra Legal

\begin{tabular}{|l|l|c|c|}
\hline \multicolumn{1}{|c|}{ Requerente } & \multicolumn{1}{c|}{ Fazenda } & Área (ha) & Módulos Fiscais \\
\hline Ivan Queiroz de Almeida & Rancho Preto & $1.027,63$ & 13,70 \\
\hline Belcina Coelho dos Santos & Rancho Alegre & $1.022,80$ & 13,73 \\
\hline Almir Leão do Amaral Filho & Vista Alegre & $1.017,77$ & 13,57 \\
\hline Kaley de Jesus Oliveira & Boa Vista & $1.045,33$ & 13,93 \\
\hline Valterli Leite Guedes Filho & Recanto & $1.047,90$ & 13,96 \\
\hline Bruno Peres de Lima & Goiânia & $1.001,53$ & 13,35 \\
\hline Pedro Henrique Guedes & Mata Linda & $1.019,75$ & 13,58 \\
\hline Jorge Marinho de Souza & Sombra da Mata & 980,73 & 13,07 \\
\hline Edson Coelho dos Santos & Flor da Mata III ${ }^{1}$ & $1.654,39$ & 22.05 \\
\hline Total & & $9.817,83$ & 130,94 \\
\hline
\end{tabular}

Fonte: organizado pelo autor, com base em dados do MDA/Incra (2017).

As famílias camponesas ocupantes da fazenda foram responsáveis por observar no dia a dia da ocupação que as áreas não possuíam divisão de cercas e marcos e eram, na verdade, um só imóvel rural situado em terras públicas.

A fraude - prestes a ser aceita pelo órgão fundiário, que havia detectado uma área bem menor - ficou clara por um erro crasso do Sr. José Iris Nunes ao requerer, junto ao Programa Terra Legal, a regularização fundiária: os documentos, entregues no ano de 2013, foram datados como tendo sido elaborados entre o período de $05 / 03 / 2006$ a 10/05/2006, mas faziam, todos eles, referência à Lei 11.952 do ano de 2009. A Figura 1 traz a folha deste documento explicitando a fraude: 
Figura 1 - Trecho de Instrumento Particular de Compra e Venda, com datação indicando fraude

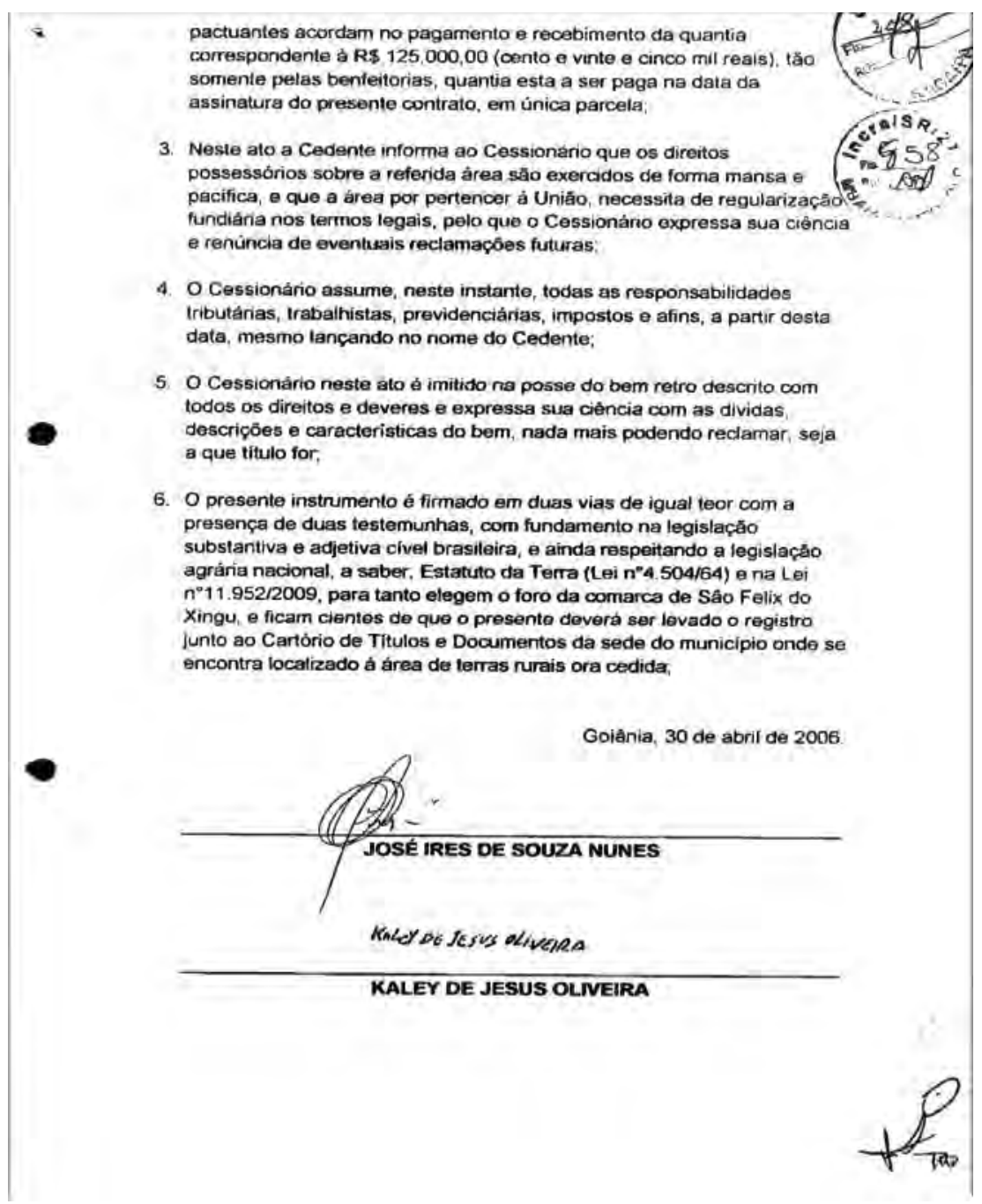

Fonte: MDA/Incra (2005).

Em cada um dos nove pedidos de regularização das parcelas do Complexo Divino Pai Eterno foi entregue uma cópia idêntica de um Instrumento Particular de Compra e Venda, da qual a folha acima faz parte, apenas com a alteração do nome do comprador e a variação em alguns dias na data. Constatado esse fato, o Programa Terra Legal suspendeu o processo de regularização fundiária e o então MDA, no ano de 2015, levou adiante os atos administrativos pertinentes à desafetação da área em disputa para a regularização fundiária, devido ao 
interesse do Incra em criar ali Projetos de Assentamento. A morosidade do órgão fundiário em constatar as irregularidades e das Justiças Estadual e Federal em determinarem a reintegração de posse para o Incra resultaram em, ao menos, seis mortes envolvendo esse conflito fundiário. Como demonstra o Quadro 2:

Quadro 2 - Acampados assassinados no conflito do Complexo de Fazendas Divino Pai Eterno

\begin{tabular}{|l|l|l|}
\hline Nome do Acampado & Ano & \multicolumn{1}{c|}{ Circunstâncias do Homicídio } \\
\hline Rogério Jesus Ferreira & 2012 & Morto a pauladas na Vila Sudoeste. \\
\hline Jocelino Braga & 2012 & Esfaqueado dentro do seu barraco no acampamento. \\
\hline Francisco Leite Feitosa & 2012 & Morto a tiros dentro da área da fazenda. \\
\hline Félix Leite dos Santos & 2014 & Morto a tiros saindo de sua roça na área da fazenda. \\
\hline Osvaldo R. Costa & 2015 & Morto a tiros no acampamento. \\
\hline Ronair José de Lima & 2016 & Morto a tiros próximo ao acampamento. \\
\hline
\end{tabular}

Fonte: organizado pelo autor com base em dados da CPT e Deca, 2017.

Não cabe, no espaço deste artigo, aprofundar as circunstâncias dos homicídios acima relacionados, mas o fato é que nem consequências tão graves conseguiram fazer com que o Estado retomasse suas terras e as destinasse, como determina a Constituição Federal de 1988, para a criação de Projetos de Assentamento. Até o início do ano de 2020, não houve a criação de nenhum projeto de assentamento na referida área, e um processo de reintegração de posse movido pelo Incra continua em andamento nas esferas judiciais.

O que se pode concluir é que as manobras jurídicas e recursos administrativos utilizados pelos advogados do grileiro objetivavam adiar a única decisão possível do ponto de vista legal ${ }^{15}$ : a retomada das terras para o patrimônio público e a criação de um PA, afinal de contas, segundo depoimento dos acampados para essa pesquisa, os gerentes do Sr. José Íris Nunes continuavam manejando gado na fazenda em fins do ano de 2018. A atuação do Estado em relação às Fazendas Divino Pai Eterno vai ao encontro à ideia de que a luta dos camponeses é a principal força contra a apropriação e a privatização das terras públicas. Enquanto o Estado, ao criar normas legais que favorecem a regularização fundiária da grilagem, incentiva e facilita a atuação dos grileiros, agindo mesmo como um dos principais esteios da acumulação espacialmente expansiva, propiciando condições para a apropriação territorial por parte de agentes privados, que destinarão essas terras para a produção agropecuária capitalista. A luta das famílias camponesas pela

15 Entre tais recursos há pedidos de reintegração de posse, não pagamento de custas processuais determinadas pela justiça, recursos até os tribunais de apelação em Brasília e outros tantos. 
terra é o que coloca a situação em um impasse. De qualquer forma, os pedidos de regularização fundiária da referida fazenda continuam, no início do ano de 2020, em análise no banco de dados do Programa Terra Legal, em nome dos prepostos do Sr. Íris Nunes e, portanto, a regularização fundiária ainda pode ocorrer.

\subsection{O CONFLITO AGRÁRIO NO COMPLEXO DE FAZENDAS IRAQUE, NO MUNICÍPIO DE ELDORADO DOS CARAJÁS}

Um caso de destaque no processo de regularização fundiária no Sudeste Paraense é o de uma área contida em uma fazenda denominada de Complexo Iraque, localizada na Gleba Sororó IV, gleba federal arrecadada pelo Incra ainda nos anos 1970 (Mapa 4), localizada no município de Eldorado dos Carajás/PA:

Mapa 4 - Localização do Complexo de Fazendas Iraque, na Gleba Federal Sororó

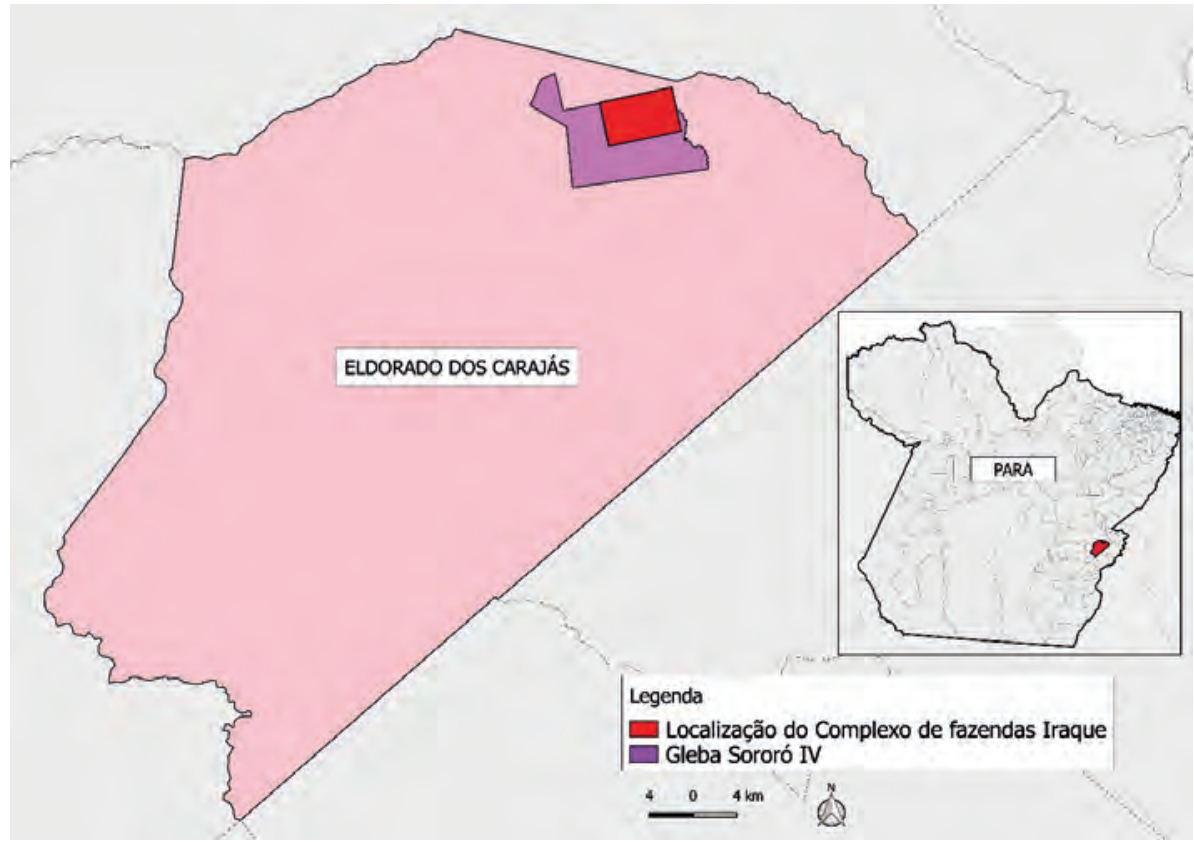

Fonte: organizado pelo autor com base em dados do MDA/Incra (2017).

Por parte do Incra, a informação obtida é de que não há título legítimo referente ao Complexo Iraque destacando-o para o patrimônio particular.

De posse de tal informação, cerca de 200 famílias camponesas ocuparam a referida fazenda, no dia 09/11/2007, organizadas por lideranças do STTR de 
Eldorado dos Carajás. Além disso, de acordo com a assessoria jurídica da CPT de Marabá, era de conhecimento do movimento social que a família detentora das terras possuía autuações pretéritas por escravizar trabalhadores. Em um auto de fiscalização do Ministério do Trabalho e Emprego (MTE) há o relato de um dos fiscais sobre o nome do pretenso proprietário do imóvel: Sr. Aurélio.

Na ocasião, houve autuação pela manutenção de trabalhadores em condições análogas à escravidão ${ }^{16}$. No entanto, processo judicial movido pelo Ministério Público do Trabalho (MPT), pelo crime previsto no Art. 149 do Código Penal, não obteve êxito, devido ao subterfúgio do fracionamento da fazenda. Durante a ação impetrada pelo MPT, o Sr. Aurélio, colocado na condição de réu, alegou que havia fracionado a área em quatro parcelas distribuídas entre seus quatro filhos (Fazendas Iraque, Água Azul, Pontal II e Esperança). Uma das frações teria mantido o nome de Fazenda Iraque sendo, supostamente, de propriedade de seu filho, José Miguel. A alegação da defesa era de que a fiscalização teria ocorrido na Fazenda Iraque, do filho do Sr. Aurélio, e não na fazenda do acusado. A primeira ação penal foi então arquivada e aberta outra, tendo como réu José Miguel. Neste outro processo, a defesa da família conseguiu dar um verdadeiro drible no sistema judicial, com a seguinte alegação: quando a fiscalização do MTE perguntou o nome do imóvel na vizinhança, foram informados que se chamava Fazenda Iraque porque as pessoas da região ainda conhecem todas as fazendas por esse nome, mas o flagrante de trabalho em condições análogas à escravidão teria sido em outra fração da fazenda, em área então denominada Fazenda Pontal II, do Sr. Pascoal, outro filho do Sr. Aurélio. O juiz admitiu, então, a existência do crime, mas não pode imputá-lo ao Sr. Miguel, absolvendo-o em decisão tomada no ano de 2012, cinco anos após a autuação pelo MTE ${ }^{17}$. A tática clássica da grilagem de fracionamento de terras provocou a impunidade da família de fazendeiros em relação à acusação de escravização de trabalhadores.

16 O coordenador do Grupo de Fiscalização Móvel do Ministério do Trabalho, responsável pela operação que autuou o fazendeiro, apontou que a única comida fornecida era arroz e farinha e que os próprios trabalhadores tinham que obter carne por meio de caça na própria fazenda, conforme consta no Processo nº 2009.39.01.0011916, Sentença, p.1, localizado na Justiça Federal de Marabá (MARABÁ, 2009).

17 É importante notar também que, durante o processo, foi constatado que o Sr. Pascoal, outro filho do Sr. Aurélio, já havia sofrido autuação pelo mesmo crime e que também detinha fazenda em área pública no Município de São Domingos do Capim/PA. E ainda um outro filho, Francisco Vitalino, já possuía uma condenação pelo mesmo crime. E como prova do fracionamento e do uso de prepostos, um dos filhos apresentado como suposto detentor de uma das frações da fazenda, é cirurgião-dentista, funcionário público e trabalha em outro estado. 
Mas voltando à questão da acusação de se tratar de terras públicas, os próprios detentores admitiam o fato, dado que todas as parcelas já possuíam pedidos de regularização efetuados anos antes da criação do Programa Terra Legal, conforme o Quadro 3:

Quadro 3 - Complexo de Fazendas Iraque, fracionado para requerimento de regularização fundiária ${ }^{18}$

\begin{tabular}{|l|l|c|c|}
\hline \multicolumn{1}{|c|}{ Requerente } & Fazenda & Área (ha) & $\begin{array}{c}\text { Ano do pedido de } \\
\text { regularização }\end{array}$ \\
\hline Francisco Vitalino & Esperança & 500 & 2006 \\
\hline Pascoal & Pontal II & 485 & 2003 \\
\hline José Miguel & Iraque & 483,31 & 2003 \\
\hline Sukarno & Água Azul & 492,02 & 2003 \\
\hline Luciana (fora do conflito) & Borborema & 500 & 2001 \\
\hline Josilene (fora do conflito) & Pontal I & Sem dados & Não requereu regularização \\
\hline
\end{tabular}

Fonte: organizado pelo autor com base em dados do MDA/Incra SR/27, 2012.

Tivesse a família aguardado mais alguns anos, com a criação do Programa Terra Legal, poderia ter solicitado, dentro dos parâmetros estabelecidos pela Lei no 11.952/09, uma área de até 1125 hectares, referentes a 15 Módulos Fiscais no município de Eldorado dos Carajás, sem a necessidade de fracionar a área em quatro fazendas e, sim, apenas em duas. E ainda, se a família de grileiros tivesse a sorte do movimento social não ocupar seu imóvel até o final do ano de 2016, quando da edição da MP no 759 pelo governo Temer, não precisaria haver o fracionamento, e o latifúndio seria legalizado por meio dessa medida legal, pois que a regularização então ficou autorizada até o limite de 2.500 hectares.

Mais uma evidência de como tais normas legais efetivamente favorecem a atuação da grilagem e da apropriação ilegal de terras públicas federais. Mesmo com todas as evidências do Complexo Iraque estar situada em gleba pública federal, houve a judicialização do conflito fundiário: três dos filhos do Sr. Aurélio entraram na Justiça e obtiveram liminar de reintegração de posse em desfavor do movimento de luta pela terra, então acampados no interior da fazenda em um acampamento denominado Jerusalém.

Os acampados foram notificados da decisão judicial pela reintegração de posse em favor dos fazendeiros, mas como o Governo do Pará não disponibilizou

${ }_{18}$ As duas últimas fazendas que aparecem no quadro não pertencem à família do Sr. Aurélio. São médias propriedades e não tiveram suas terras ocupadas pelo movimento social. 
forças policiais para a desocupação, os integrantes decidiram por não a cumprir. Por cinco anos, as famílias continuaram acampadas sem certeza do desfecho final. Somente no ano de 2013, o juiz Jonas da Conceição Silva, da Vara Agrária de Marabá, decidiu pela improcedência da reintegração de posse e transferiu para o Incra a decisão sobre a destinação das terras. $\mathrm{O}$ argumento do juiz baseou-se na impossibilidade da posse em terras públicas federais dessa extensão. Nesse caso, de acordo com o magistrado, há mera detenção, sem se fazer jus aos direitos possessórios. Houve, no entanto, por parte do fazendeiro, recurso para o TJPA, que manteve a improcedência da reintegração de posse.

Outro recurso foi dirigido ao STJ, o qual não se manifestou sobre o caso até os dias atuais. Passados treze anos da ocupação das terras do Complexo de Fazendas Iraque pelas famílias organizadas pelo ST'TR, o Projeto de Assentamento não foi criado e nem há a perspectiva de que venha a ser, sobretudo pelo fato do acampamento ter se desmobilizado, e as terras continuarem nas mãos dos grileiros. De acordo com o Programa Terra Legal, as fazendas seriam divididas da seguinte forma:

a) Fazendas Esperança, Água Azul e Iraque não foram habilitadas para regularização. A vistoria do Programa Terra Legal apontou o desmatamento integral em todas as três fazendas. Não obstante, os impeditivos indicados pelos técnicos para o indeferimento foram o conflito fundiário, dada a ocupação das terras por famílias camponesas, e a autuação do MTE por trabalho degradante e em condições análogas à escravidão em relação às Fazendas Esperança e Água Azul. O que dá a entender que todas estariam aptas a ser regularizadas não fossem as atuações do movimento social e do MTE. De qualquer forma, todas as três encontram-se, no ano de 2020, como estando em análise no Programa Terra Legal e, com a desmobilização dos acampados e a aposta do governo Bolsonaro na regularização fundiária para favorecer o agronegócio, nada impede que venham a ser regularizadas em futuro próximo.

b) Fazenda Pontal II: segundo a equipe do Programa Terra Legal, “é uma fazenda típica da região com atividade principal na pecuária. Esta fazenda, de todas as que formam o Complexo Iraque, é a com maior quantidade de mata preservada, entre 30\% a 40\%. Pastagem muito degradada, sendo em alguns pontos considerados capoeiras. Casa Sede abandonada com curral em desuso". Foi justamente nessa parcela que o MTE flagrou trabalhadores em condição de trabalho análoga à escravidão, no ano de 2006. Mesmo assim cogitou-se dessa 
área entrar como parte de um acordo judicial e ser regularizada em nome da família do Sr. Aurélio. No início do ano de 2020, esta também continua sendo utilizada pela família de fazendeiros e consta nos bancos de dados do Programa Terra Legal como estando em análise.

c) Fazenda Pontal I: não houve pedido de regularização, nem ocupação pelo movimento e, por ora, continuará na mão do detentor atual.

d) Fazenda Borborema (fora do conflito): laudo do então MDA a considerou apta para a regularização fundiária em nome da Sra. Luciana, que não pertence à família detentora das demais áreas, ainda que tenha sido detectada uma taxa de desmatamento de 74\% do imóvel, demonstrando o descumprimento de um dos itens da função social da terra. Desde 2015, o imóvel encontra-se em análise no Programa Terra Legal com a indicação, por técnicos do programa, da viabilidade da regularização. A fazenda, típica da região, e que possui até 1.200 cabeças de gado e até dez funcionários dependendo da época do ano, tende a ser legitimada pelo Programa Terra Legal como propriedade privada da Sra. Luciana.

O resumo de todo esse conflito é que a totalidade da área, situada em gleba pública federal, com taxas de desmatamento acima da legalidade e com de trabalhadores tratados como escravizados, continuará, por ora, a ser apropriada pela pecuária extensiva e em grande escala. O quadro clássico da acumulação espacialmente expansiva, uma das formas da acumulação por expropriação, se completa no caso em análise com as ameaças à vida do coordenador do acampamento, Sr. Edvaldo Moura da Silva (CPT, 2012, p. 135). Como no primeiro caso estudado, também no conflito instalado no Complexo de Fazendas Iraque, para que se efetue a separação entre os produtores diretos e os meios de produção, houve a prevalência da fraude, do desmatamento ilegal, da grilagem, dos métodos ilegais de se obter riqueza ou ainda o aproveitamento das oportunidades criadas pelas normas legais para a apropriação privada de terras públicas federais.

\section{CONSIDERAÇÕES FINAIS}

À revelia da lei, desmatando, escravizando e assassinando, a apropriação de terras públicas é, historicamente, um fator central nos processos de acumulação no Brasil e, particularmente, em regiões da Amazônia Legal. No Sudeste Paraense, é mesmo o padrão de normalidade de ocupação territorial vigente há décadas. Trata-se de uma acumulação espacialmente expansiva, centrada no avanço da 
grilagem em áreas devolutas e, frequentemente, em áreas de mata nativa. O Estado anui a tudo, com sua atuação contumaz em anistiar e incentivar tais apropriações ilegais de terras devolutas. Os dois casos aqui estudados demonstram claramente tal situação, em detrimento do avanço da reforma agrária e da territorialização de famílias camponesas, que ainda preservaram frações dessas terras ou impediram a regularização no nome dos pecuaristas devido, quase que exclusivamente, à sua resistência por anos nos acampamentos. Não fosse essa luta, a extensão total dessas áreas estaria nas mãos dos pecuaristas e, pior, com a propriedade devidamente formalizada.

Regularizadas ou não, a depender da capacidade operacional dos órgãos fundiários, as terras públicas ocupadas pela grilagem e pela pecuária capitalista não são retomadas e continuam a servir de condição fundamental para a acumulação capitalista e um elo indispensável dos mercados nacional e internacional de carne bovina. Uma vantagem competitiva brasileira no mercado internacional. Os Complexos de Fazendas Divino Pai Eterno e Iraque são apenas exemplos da prática usual, na região, de acumulação espacialmente expansiva alimentando a reprodução ampliada do capital: não são anacrônicos e não devem servir como indicadores de um suposto atraso regional, dado que estão articulados com os setores considerados modernos da produção capitalista. São elos mesmo da interligação entre a reprodução propriamente capitalista, voltada para o mercado internacional, mas que tem suas bases e suas condições fornecidas pela acumulação espacialmente expansiva possibilitada por meios não econômicos.

Portanto, a apropriação privada de terras públicas, mesmo que por meios não econômicos, é uma das faces da economia capitalista moderna. As sucessivas leis de regularização fundiária editadas nas últimas décadas só fazem incentivar tal prática a despeito das anunciadas intenções em regularizá-la para aumentar a segurança jurídica ou ampliar a possibilidade de investimentos nestas regiões.

\section{REFERÊNCIAS}

BRASIL. Lei no 601, de 18 de setembro de 1850. Dispõe sobre terras devolutas [...]. Rio de Janeiro: Palácio Imperial, [1850]. Disponível em: http:// www.iterpa.pa.gov.br/sites/default/files/lei_n.o_601_de_18_de_setembro_ de_1850.pdf. Acesso em: 03 ago. 2020. 


\section{BRASIL. [Constituição 1891]. Constituição da República dos Estados} Unidos do Brasil. Rio de Janeiro: Congresso Nacional, 1891.

BRASIL. Decreto-Lei no 1.164 , de $1^{\circ}$ de abril de 1971. Declara indispensáveis à segurança e ao desenvolvimento [...]. Brasília, DF: Presidência da República, [1971]. Disponível em: encurtador.com.br/hsEIW. Acesso em: 03 ago. 2020.

CÍCERO, J.; BARroS, C. A espera que sangra o Divino Pai Eterno. Publica, São Paulo, 17 out. 2016. Especial: Amazônia em disputa. Disponível em: https://apublica.org/2016/10/a-espera-que-sangra-o-divino-pai-eterno/. Acesso em: 07 abr. 2020.

CUNHA, C. N.; TORRES, M.; GUERRERO, N. R. Ri por último quem grila melhor. In: SIMPÓSIO INTERNACIONAL DE GEOGRAFIA AGRÁRIA, 6., 2011, Belém. Anais [...]. Belém: UFPA, 2011. p. 1-11.

DE ANGELIS, M. Marx e acumulação primitiva - o caráter contínuo das "vedações" do capital. O Comuneiro, [S. l.], n. 26, 2018. Disponível em: https:// www.ocomuneiro.com/nr26_2_MassimodeAngelis.html\#: :text=Uma\%20 vez $\% 20$ que $\% 2$ C $\% 20$ para $\% 20$ Marx, $\% 22$ base $\% 22 \% 20$ da $\% 20$ pr $\%$ C3 $\%$ B 3 pria $\% 20$ acumula $\%$ C3\%A7\%C3\%A3o. Acesso em: 03 ago. 2020.

ÉLERES, P. Intervenção territorial federal na Amazônia. Belém: Imprensa Oficial do Estado, 2002.

EMMI, M. F. A oligarquia do Tocantins e o domínio dos castanhais. Belém: UFPA/NAEA, 1999.

FORSTER, G. R. A privatização das terras rurais. São Paulo: Manole, 2003.

IBGE. Pesquisa pecuária municipal. IBGE, Rio de Janeiro, 2019. Disponível em: http://www.ibge.gov.br. Acesso em: 25 mar. 2021.

IBGE. Divisão Regional do Brasil. IBGE, Rio de Janeiro, 2020. Disponível em: http://www.ibge.gov.br. Acesso em: 25 mar. 2021.

MARABÁ. Justiça Federal. Ação Penal. No 2009.39.01.001191-6. Redução a condição análoga à de escravo. Réu José Miguel Oliveira. $1^{\mathrm{a}}$ Vara de Marabá. 2009. Diário da Justiça, 2009.

MARTINS, J. S. O cativeiro da terra. São Paulo: Hucitec, 1998.

MDA/INCRA. Processo no 54600.000045.2005-19. Levantamento de área para reforma agrária - Fazenda Rancho Grande (Divino Espírito), fl. 463, Marabá, 2005.

MDA/INCRA. Lista de posseiros cadastrados. Brasília, DF: INCRA, 2017. Disponível em: http://www.incra.gov.br. Acesso em: 25 mar. 2021. 
MONTEIRO, B. Direito agrário e processo fundiário. Rio de Janeiro: PLG Comunicação, 1980.

MOT'TA, M. M. M. Nas fronteiras do poder: conflito e direito à terra no Brasil no século XIX. Rio de Janeiro: Vício de Leitura/Arquivo Público do Estado do Rio de Janeiro, 1998.

NOVOA, H. Discriminação das terras devolutas. São Paulo: Livraria Editora Universitária de Direito, 2000.

OLIVEIRA, A. U. A fronteira amazônica mato-grossense: grilagem, corrupção e violência. São Paulo: Iãnde Editorial, 2016.

OLIVEIRA, A. U.; FARIA, C. S.; BUARQUE DE HOLLANDA, T. P.

Registros públicos e recuperação de terras públicas. Brasília, DF: Ministério da Justiça, 2012. (Relatório Final, série Pensando o Direito, n48, Brasília).

PARÁ. Decreto Estadual no 410, de 08 de outubro de 1891. Regula a alienação das terras devolutas [...]. Belém: Palácio do Governo, [1891].

Disponível em: https:/ / arisp.files.wordpress.com/2009/07/decreto-estadual-nc2ba-410-de-8-de-outubro-de-18911.pdf. Acesso em: 03 ago. 2020.

PEREIRA, A. R. O papel dos mediadores nos conflitos pela posse da terra na região Araguaia Paraense: o caso da fazenda Bela Vista. 2004. 205 f. Dissertação (Mestrado em Extensão Rural) - Programa de Pós-Graduação em Extensão Rural, Universidade Federal de Viçosa, Viçosa, 2004.

SILVA, L. O. Terras devolutas e latifúndio: efeitos da Lei de 1850. Campinas: Editora da Unicamp, 1996.

TERENCE, M. F. A acumulação capitalista entre o sangue e a imundice: processos de privatização de terras públicas federais no Sudeste Paraense. 2018. 401 f. Tese (Doutorado em Geografia Humana) - Programa de Pós-Graduação em Geografia Humana, Faculdade de Filosofia, Letras e Ciências Humanas, Universidade de São Paulo, São Paulo, 2018.

TORRES, M. Terra privada, vida devoluta: ordenamento fundiário e destinação de terras públicas no oeste do Pará. 2012. 878 f. Tese (Doutorado em Geografia Humana) - Programa de Pós-Graduação em Geografia Humana, Faculdade de Filosofia, Letras e Ciências Humanas, Universidade de São Paulo, São Paulo, 2012.

TRECCANI, G. D. Violência e grilagem: instrumentos de aquisição da propriedade da terra no Pará. Belém: UFPA/Iterpa, 2001. 
